\title{
Ensino e Aprendizagem e a Resiliencia.
}

Teaching and Learning and Resilience.

\author{
Relindes Dalva De Assis \\ Universidade Federal de Mato Grosso (UFMT)-Brasil \\ relindesdalva@hotmail.com
}

Fecha recepción: 14/10/2019

Páginas 26-37

Fecha aceptación: 25/11/2019

\section{Resumo.}

O processo de ensino aprendizagem, é algo que nos chama atenção pois necessita da construção de estratégias de enfrentamento das problemáticas existentes dentro do ambiente escolar e assim contribuir para a ampliação das possibilidades de melhoria do ensino aprendizagem. O resiliência vivenciado no contexto escolar apresenta algumas formas como objetivo e ferramentas para a concretização do ensino aprendizagem. Nesse contexto, o presente artigo visa analisar como o termo resiliência é conceituado por diversos teóricos e qual sua contribuição no processo ensino aprendizagem. Como percurso metodológico foi realizada revisão bibliográfica e portanto, é relevante os estudos que aprofundem a temática em questão já que a pedagogia da resiliência se coloca como possibilidade de potencializar o acesso igualitário do conhecimento a todos os educandos.

Palavras-chave: ensino; aprendizagem; estratégia; resiliência

\begin{abstract}
.
The teaching-learning process is something that catches our attention because it needs the construction of strategies to confront the existing problems within the school environment and thus contribute to the expansion of the possibilities for improving teaching learning. The resilience experienced in the school context presents some forms as objective and tools for the realization of teaching and learning. In this context, this article aims to analyze how several theorists conceptualize the term resilience and what its contribution to the teaching-learning process. As a methodological path, a bibliographic review was carried out and, therefore, studies that deepen the theme in question are relevant since the pedagogy of resilience is posed as a possibility of enhancing the equal access of knowledge to all students.
\end{abstract}

Keywords: teaching; learning; strategy; resilience 


\section{1.-Introdução.}

O processo de aprendizagem é constituído por desafios próprios à escolarização. Este trabalho apresenta um levantamento de teorias acerca do conceito de resiliência, uma temática da Psicologia do Desenvolvimento Humano, que é um conceito relativamente recente com algumas divergências entre autores. Constata-se que no campo das ciências humanas e em especial na área da educação a resiliência não é quantificável ou mensurável, contudo, sugere a capacidade de enfrentamento perante as dificuldades encontradas. A pesquisa foi feita através de revisão bibliográfica em artigos científicos, verificando-se que para este tema são encontrados estudos variados com enfoques diversos. Neste trabalho buscou-se abranger o máximo de trabalhos possíveis, dentro da linha de conhecimento pretendido, no que concerne ao conceito e suas derivações, nos trabalhos pesquisados foi possível observar as condições básicas para resiliência.

Abordaremos o tema em três etapas, sendo a primeira uma definição do conceito, suas atribuições e desdobramentos, bem como as ciências que primeiro a usaram e suas orientações; a segunda parte será sobre 0 ensino e aprendizagem, e na terceira etapa será abordado o tema sobre o ensino aprendizagem e a resiliência, dentro de uma abordagem bibliográfica, verificando livros, artigos, dissertações e teses já apresentadas dentro dos últimos quinze anos; sendo que a resiliência exige uma aprendizagem de construção compartilhada, entre professor e aluno de maneira continua e crescente.

Este trabalho pode ser útil socialmente, por buscar identificar um novo aspecto do conceito de resiliência, podendo ser passivel na construção do conhecimento e discussão sobre diferentes modalidades de ajuda psicossocial no momentos de catástrofes e calamidades, bem como no aprendizado e trato do dia a dia.

0 presente estudo justifica-se por apresentar reflexões e possíveis caminhos que nascem de uma visão otimista do ser humano através dos estudos sobre a resiliência. Acredita se na relevância deste conceito e seus efeitos positivos em estreitar laços entre professores e alunos, já que estarão mais conscientes da importância de assumirem uma postura de superação, mas também de reconhecimento de sua própria individualidade, frente às adversidades cotidianas.

\section{2.-Resiliência.}

Historicamente falando, a noção de resiliência vem sendo utilizada há muito tempo pela Física e Engenharia, sendo um de seus precursores o cientista inglês Thomas Young. Em 1807, ele descreveu experimentos sobre tensão e compressão de barras, buscando a relação entre a força que era aplicada num corpo e a deformação que essa força produzia.

0 termo resiliens, na origem latina, significa saltar, voltar, ser impelido, recuar, encolher-se, romper. No dicionário de língua portuguesa, o termo é referido aos materiais: "propriedade pela qual a energia armazenada em um corpo deformado é devolvida quando cessa a tensão causadora duma deformação elástica. [...] Resistência ao choque" (Ferreira, 1999, p. 1751). 
Em inglês, resilience ou resiliency significa (a) capacidade para se recuperar a partir de choques, ferimentos e traumas; (b) capacidade de os animais e plantas se recuperarem rapidamente de lesões e danos; e (c) capacidade de objetos, depois de ser dobrados, esmagados e deformados combinarem força e resistência e voltar à forma original (Crowther, 1995). Todas essas definições apontam para significados que indicam a diferenciação de objetos, materiais e seres vivos por sua capacidade de resistência, em relação a outros elementos que a eles são semelhantes.

Para Yunes e Szymanski (2001, p. 16), "a psicologia, na verdade, apropriou-se de um conceito construído dentro de um modelo matemático e há de haver cautela para que não ocorram comparações indevidas". Não há como comparar a resiliência de materiais com a resiliência como um processo psicológico, até porque o conceito de deformação em Física e em Psicologia são incomparáveis. Poletto e Koller (2008) afirmam que a ideia de voltar à forma original após o impacto de um estressor está superada, pois "o sujeito aprende, cresce, desenvolve e amadurece" (p. 17), portanto, se transforma.

Quando se refere ao processo de resiliência no ser humano, Rutter (1991 apud Marques, 2008), afirma que essa qualidade se caracteriza por um conjunto de processos sociais e intrapsíquicos que possibilitam à pessoa ter uma vida saudável num meio adverso. Ela é advinda das discussões da Psicologia positiva, que coloca os indicadores saudáveis necessários aos sistemas adaptativos no processo de desenvolvimento humano, trata-se de um processo de construção que se desenvolve ao longo do tempo e resulta da influência da família, dos suportes sociais e da educação.

A palavra resiliência geralmente é utilizada para se referir à superação de momentos ou situações difíceis e principalmente a capacidade do indivíduo de enfrentar essas situações e outras adversidades, bem como ser transformado por elas (Yunes, 2003; Pinheiro, 2004). 0 estudo da resiliência e em especial dos mecanismos protetivos, corrobora a inversão do predomínio dos aspectos negativos, patológicos, de desordens de inadaptação humana presentes nos referenciais teóricos da psicologia em geral. (Yunes, 2003)

No Brasil, o uso do conceito de resiliência é recente. 0 Dicionário Michaelis (1998), define a palavra resiliência como "ato de retorno de mola; elasticidade; ato de recuar (arma de fogo); coice; poder de recuperação; trabalho necessário para deformar um corpo até seu limite elástico" (p.1826), não dando nenhum espaço à outra significação da palavra. No dicionário Houaiss (2008), já surge a definição no sentido figurado, como "capacidade de recobrar ou de se adaptar à má sorte, as mudanças" (p. 649).

Na Wikipédia, a enciclopédia livre apresenta a definição de resiliência como a capacidade de 0 indivíduo lidar com problemas, adaptar-se a mudanças, superar obstáculos ou resistir à pressão de situações adversas - choque, estresse, algum tipo de evento traumático, etc. Sem entrar em surto psicológico, emocional ou físico, por encontrar soluções estratégicas para enfrentar e superar as adversidades. Nas organizações, a resiliência se trata de uma tomada de decisão quando alguém se depara com um contexto entre a tensão do ambiente e a vontade de vencer. Essas decisões propiciam forças estratégicas na pessoa para enfrentar a adversidade.

No Dicionário de Português Online, encontramos três definições para o termo: 
1.-Capacidade de recuperação ou restabelecimento de um ser vivo perante um agente perturbador, uma situação adversa ou um obstáculo; resistência, força; estoicismo: a resiliência das crianças é impressionante;

2.-(Mecânica) propriedade que um material possui que lhe permite resistir ao choque. 3.-(Física) habilidade que um corpo tem de recuperar a sua forma original após ficar deformado ou sofrer uma colisão.

Melillo (2005), afirma que um dos primeiros elementos que aparecem na literatura dos últimos anos é o acordo explicito entre os especialistas em resiliência, que já levam duas gerações pesquisando o tema. A primeira, dos anos 1970, procura identificar os fatores de risco e de resiliência que influem no desenvolvimento de crianças que se adaptam positivamente, apesar de viverem em condições de adversidade. Já a segunda, nos anos 1990, foca no estudo da dinâmica entre fatores que estão na base da adaptação resiliente. (Melillo, 2005).

Para Yunes (2003 apud Pinheiro 2004), a resiliência é um fenômeno que procura explicar os processos de superação de adversidades, mas não se confunde com invulnerabilidade, pois não é uma resistência absoluta às adversidades. De acordo com Yunes (2001) existem no dicionário de língua inglesa dois raciocínios para o termo resiliência que se aplicam tanto a materiais quanto a pessoas. 0 primeiro se refere à habilidade de voltar rapidamente para o seu estado normal de saúde ou de espírito depois de passar por doenças e dificuldades, por exemplo. A segunda acepção diz respeito à propriedade de uma substância retornar à sua forma original quando a pressão é removida. Esta última remete ao conceito original atribuído à Engenharia e à Física que busca estudar até que ponto um material sofre impacto, volta ao seu estado original e não fica deformado quando tais forças deixam de atuar sobre o mesmo.

Para Flach (1991, apud Pinheiro, 2004) o uso do termo vem de 1966, visando descrever as forças psicológicas e biológicas exigidas para atravessar com sucesso as mudanças na vida, e sua ideia é que o indivíduo resiliente tem habilidade para reconhecer a dor, perceber seu sentido e tolerá-la até resolver os conflitos de forma construtiva para si mesmo.

Os pesquisadores da segunda geração entendem resiliência como "um processo dinâmico em que as influências do ambiente e do indivíduo interatuam em uma relação reciproca, que permite a pessoa se adaptar, apesar da diversidade" (Melillo, 2005 p. 25).

Silva e Alves (2007) consideram que o antigo conceito de resiliência, contemplado na teoria do traço, recebeu um novo significado, emoldurado na capacidade que o ser humano tem de sobreviver em diferentes períodos da história humana. Passou-se a levar em conta os efeitos entre múltiplos fatores, considerando-se também a dinâmica entre os aspectos internos e externos aos sujeitos, como a aquisição de afetos, a importância de um apego seguro, a estrutura familiar, o nível socioeconômico, a cultura e a educação. Ou seja, gradativamente atentou-se a interação entre aquilo que é subjetivo e aquilo que o meio externo oferece como suporte ao sujeito.

O conceito de resiliência é mais rico e completo do que apenas o sentido que the é dado da capacidade de superar-se. Ele comporta duas dimensões: 1) a resistência à destruição, a capacidade de proteger sua integridade sob fortes pressões; 2) e 
também a capacidade de construir, de recriar uma vida digna a despeito das circunstâncias adversas e mesmo, por causa delas. Poletti e Dobbs (2007) descrevem três aspectos de manifestação da resiliência: (1) em situações onde exista um grande risco provocado por acumulação de fatores de estresse e de tensão; (2) quando a pessoa é capaz de conservar aptidões em face do perigo e seguir crescendo e se desenvolvendo; (3) quando há cura de um ou vários traumas seguidos de sucessos na vida (Poletti; Dobbs, 2007).

\section{3.-Ensino e Aprendizagem.}

Ensinar é a atividade que tem por finalidade que o outro obtenha o conhecimento. Para que se tenha um ensino de forma que realmente agregue valor é preciso que 0 professor como sendo um transmissor de conhecimentos se utilize de métodos e técnicas adequadas que tenham base não apenas no contexto geral como o local, assim a necessidade básica do aluno (aprendiz) será encarada como uma ponte para o ensino e não como um obstáculo.

Segundo Libâneo (1994, p. 90) "a relação entre ensino e aprendizagem não é mecânica, não é uma simples transmissão do professor que ensina para um aluno que aprende." Ele mesmo concluiu que é algo bem diferente disso "é uma relação recíproca na qual se destacam o papel dirigente do professor e a atividade dos alunos." Dessa forma podemos perceber que "O ensino visa estimular, dirigir, incentivar, impulsionar o processo de aprendizagem dos alunos."

Ensinar envolve toda uma estrutura que tem por finalidade alcançar a aprendizagem do aluno através de conteúdo. A relação de ensino e aprendizagem não deve ter como base a memorização, por outro lado os alunos também não devem ser deixados de lado sozinhos.

Quando se está em sala de aula o professor tem por objetivo que os alunos que ali estão presentes saiam com o conteúdo assimilado, este, portanto é seu objetivo, para que este objetivo seja alcançado o professor irá se utilizar de um método, que de forma simples é o caminho realizado para se atingir um objetivo, passa pelos métodos que são os meios para realizar objetivos (Libâneo, 1994). Os métodos que serão empregados vão depender do local, idade, nacionalidade, realidade social e diversos outros fatores que influenciam a forma de aprender do aluno. Assim, para algumas turmas o método expositivo será de maior aceitação e com uma melhor aprendizagem, já em outra turma pode acontecer que seja necessário a elaboração conjunta ou outros métodos. De qualquer maneira a forma que a aula irá ser ministrada depende da turma e da forma que o professor encara seu local de trabalho.

Em sua tese Barroso (2015), traz a importância da escolha do método na realização de uma aula, é colocado como exemplo o ensino de jovens adultos, fica clara a necessidade de se adequar as aulas para uma classe que possui uma rotina diferente de alunos que cursam em horários como matutino e vespertino. Por isso 0 professor que se encontra com uma turma como essa tem que ter noção de que a forma que eles irão aprender é diferente da forma tradicional. Não apenas no ensino de jovens adultos, como a educação para moradores de povoados, ou seja a educação do campo, ensino para presidiários, ensino para pessoas com deficiência, 
todas devem ser vistas de forma especial, e por esse motivo o professor deve estar preparado para uma nova forma de ensino que vise a aprendizagem dos alunos.

Dito de forma resumida, os métodos que serão aplicados devem possuir em mente as necessidades dos alunos, só assim a aprendizagem será obtida de forma efetiva, pois o professor irá relacionar os conteúdos com base no contexto social de cada ambiente onde ele está inserido. De nada adianta querer transmitir conteúdos muito complexo para alunos que nem mesmo possuem o domínio da leitura ou não sabem realizar contas simples. Por isso o método é tão importante, o professor através da observação vai ser capaz de descobrir quais os pontos fortes e fracos da turma e qual a melhor maneira deles aprenderem. Cada método possui uma função seja a de estimular 0 aluno ao debate ou de ajudá-lo a compreender algum conteúdo no âmbito de sua realidade local.

Não existe o melhor método, o que existe são melhores momentos para se aplicar uma técnica de ensino. Para a construção de uma aula o professor se utiliza de materiais como o livro didático, o quadro, filmes, slides, ou simplesmente a linguagem oral, Libâneo (1994) faz uma exortação quanto o domínio desses métodos, deve também ter consciência de que cada método ou técnica se adéqua a um conteúdo sendo necessário que o professor entenda que o mesmo método pode não funcionar com outro assunto.

Podemos notar que o processo de ensino e aprendizagem não é algo simples, ele engloba diversas medidas que devem ser tomadas ou evitadas para que 0 aprendizado do aluno realmente aconteça. É necessário assim, que o professor realize um planejamento de suas aulas levando em consideração as necessidades dos alunos, a melhor maneira de aplicar um conteúdo, o melhor método e técnica a ser usada em determinados momentos. Perceber o contexto social dos alunos também é importante para que seu conteúdo e exemplos sejam presentes na realidade dos alunos. Nos dizeres de Freire (1996), é de convocar os educadores para construir as bases educacionais.

Sendo assim, quanto mais amplos forem os mecanismos e estratégias que 0 sujeito, (professor) aplica, maiores serão as chances de desenvolver-se de modo saudável dentro deste ambiente, apesar das adversidades que enfrentam, e a isto denominamos resiliência neste contexto. Para esses alunos que enfrentam essas adversidades, a sala de reforço é um ambiente que propicia não somente a aprendizagem como também a interação professor-aluno, auxiliando desta forma em seu desenvolvimento. Sendo que: "[...] a partir da compreensão da interação do indivíduo com seu ambiente, implica o entendimento também dinâmico dos chamados fatores de risco e de proteção." (Carvalho, 2007, p. 2025). E neste caso, os fatores de proteção, como aceitação do grupo, professor consciente, contribuem de maneira significativa para aprendizagem de cada sujeito.

Numa ótica crítica, no desenvolvimento racional e científico para termos pessoas mais conscientes e com possibilidades de avaliar sua própria condição de vida. É nesse trilho, que os professores, a partir da resiliência, podem alterar a sua prática pedagógica.

Dessa forma, a resiliência pedagógica, desenvolvida pelos professores cria possibilidades de contemplar meios para superar o pessimismo educacional que nos atinge e trocá-lo por um realismo concreto que possa conviver e superar as 
adversidades, acompanhando as mudanças que estão ocorrendo na sociedade, levando a melhoria do ensino aprendizagem.

\section{4.-Resiliência e o Ensino Aprendizagem.}

A capacidade das pessoas manterem-se íntegras e conseguirem superar as adversidades do caminho chama-se resiliência (Antunes, 2007; Costa, 1995; Cyrulnik, 2004; Poletti \& Dobbs, 2007). Na perspectiva da resiliência, a experiência formativa tem como objetivo despertar as potências do humano que habitam em cada um de nós, através de uma visão integral.

As definições, para o termo parecem equivalentes, mesmo porque falam de adversidades, danos ou ameaças e de uma resposta positiva a isso, por ser definições para o termo, parecem apontar para um mesmo fenômeno, que os estudos são deveras amplos e tendo olhares diferentes, mesmo que a definição sejam parecidas.

A literatura mostra cinco características da resiliência, as quais podem ser atribuídas também ao professor:

(1) comunicação, que representa a possibilidade de elo e troca com os outros;

(2) capacidade de assumir a responsabilidade por sua própria vida;

(3) consciência limpa, o que significa não ceder à culpa interna, aceitar responsabilidades, reconhecer erros e superá-los;

(4) ter convicções sobre alguns valores essenciais que permitem avançar e suportar adversidades. Poletti e Dobbs, $(2007$, p. $67 ; 68)$ citam Carl Jung para dizer que: "encontrar um sentido e um significado torna suportáveis muitas coisas, talvez até torne suportáveis todas as coisas";

(5) ter compaixão, o que permite estar envolvido pelo outro e colocar-se em seu lugar para compreendê-lo tão importante quanto a si mesmo.

Conforme Silva, Alves e Motta (2005) há professores que apresentam maior resistência aos fatores agressores encontrados na prática, criando alternativas para controlar os desafios e responder às dificuldades, reagindo às adversidades e mostrando se capazes de recuperação das agressões sofridas, conseguindo, assim, diminuir seu estresse. Esses profissionais detêm características que fortalecem a resiliência.

A resiliência pedagógica, reflete em ações desenvolvidas pelos professores no cotidiano escolar para enfrentar situações problemáticas que envolvem os alunos. Como questões da falta de interesse em vir para a escola, dificuldades na aprendizagem, atos de violência e desrespeito aos colegas e funcionários da escola.

O foco no indivíduo, na sua capacidade de autoestima e autonomia caracterizavam as pesquisas pioneiras que consideravam que a resiliência existiria por uma constituição singular do indivíduo, como traço de personalidade, ao passo que existiriam os não-resilientes, não dotados de capacidade para resistir ou para enfrentar as adversidades. Essa concepção ainda vinha associada à ideia de a resiliência ser uma característica mais inata do que passivel de ser adquirida.

Para a autora Assis, (2005), a resiliência não é um atributo que nasce com o sujeito, mas sim uma qualidade que nasce da relação da pessoa com o meio em que ela vive; e que pode fortalecê-la para superar as dificuldades e violências vividas. Desta 
forma, a resiliência pode ser trabalhada e estimulada por qualquer grupo social ou instituição escolar, comunidades, profissionais, famílias (Assis, 2005, p. 7).

A compreensão destas posturas pode estar em estudos desenvolvidos pela Psicologia. Para Poletti e Dobbs (2007) há mais de quarenta anos está ciência tem se interrogado sobre o fato de que certas pessoas têm a capacidade de superar as piores situações, chamada de resiliência ativa, enquanto outras ficam aprisionadas na infelicidade e na angústia, presos nas teias da tristeza que se abatem sobre elas, não conseguindo libertar-se.

Ao refletir sobre os programas para o ensino Lousada (2004) alerta a situação para altera-los quando necessário para fazer uma relação entre o sistema de ensino e 0 próprio aluno. Nesse sentido: "Talvez o problema com grande número de educadores é não perceber a insuficiência dos argumentos racionais para interessar os alunos pelo estudo. Parece que não basta a motivação extrínseca, tentando fazer 0 estudante interessar-se pelos estudos porque isto é bom para o futuro, ou mesmo que "estudar é gostoso". É preciso fazer uma escola que estudar seja de fato gostoso" (Paro, 2000, p.16).

Wolin e Wolin (1993) identificam sete passos de desenvolvimento da resiliência ativa, por favorecerem o enfrentamento efetivo das situações adversas:

(1) tomada de consciência, ou capacidade de identificar os problemas e suas raízes e procurar soluções;

(2) independência, baseada na capacidade de estabelecer limites entre si mesmo e as pessoas próximas, não se deixando envolver pela corrente adversa;

(3) desenvolvimento de relações satisfatórias com os outros;

(4) iniciativa que permite se controlar e controlar seu ambiente tendo prazer ao realizar atividades construtivas;

(5) capacidade de pensar de forma diferente dos outros e encontrar refúgio num mundo imaginário quando necessário;

(6) humor, cujo objetivo é diminuir a tensão interior e desvendar o lado cômico das tragédias;

(7) ética, como guia da ação, e frente ao risco de viver com base nesses valores. A ética permite também a ajuda mútua e a compaixão (Wolin; Wolin, 1993).

Para Henderson e Milstein (2005) torna-se imprescindível que a escola desdobre todo o potencial e recursos ao seu alcance para conseguir uma comunidade educativa inclusiva e resiliente. Os autores descrevem os seis passos que estimulam a construção de características próprias de um docente resiliente. São eles:

(1) enriquecer os vínculos;

(2) determinar limites claros e fortes;

(3) ensinar habilidades para a vida;

(4) proporcionar afeto e apoio;

(5) estabelecer e transmitir expectativas elevadas;

(6) proporcionar oportunidades de participação significativa.

A combinação desses seis passos produz como resultado maior apego à escola, mais compromisso social e concepção mais positiva de si mesmo por parte dos alunos, pais, responsáveis e docentes (Henderson; Milstein, 2005).

A forma com que a resiliência se apresentará dependerá também de como os envolvidos (professores e alunos) enfrentarão as adversidades. E para entender esse 
enfrentamento, podem ser utilizadas estratégias da técnica de coping, que muitas vezes não serão suficientes.

O Coping tem sido descrito como um conjunto das estratégias, de esforços cognitivos específicos, utilizadas pelas pessoas para se adaptarem a situações estressantes. Algumas pessoas costumam traduzir a palavra como "estratégias de confronto", "formas de lidar com" (Pereira, 2001).

Assis, Pesce e Avanci (2006) explicam que coping "é mais do que um único mecanismo de adaptação; é um constante processo adaptativo do qual o indivíduo lança mão ao administrar adversidades cotidianas e inesperadas, vencendo-as, minimizando-as ou tolerando-as" (p. 88). Brandão (2009) destaca que é fundamental esclarecer que as estratégias de coping fazem parte do processo de resiliência, uma vez que o enfrentamento das adversidades é uma fase do mesmo. No entanto, coping não é resiliência. Além disso, nem toda estratégia de enfrentamento é bem sucedida e, por isso, nem sempre resultará em resiliência, que é visto como a estruturação da personalidade.

A aprendizagem será adquirida a partir da relação entre sujeito e objeto, na qual temos como principal na relação, o sujeito. Esta aprendizagem é construída pelo sujeito e se torna próprio deste, pois o mesmo não apenas o ouviu de outro, mas experimentou através do contato e do confronto com o ensino.

Quando parte-se da ideia de que o sujeito constrói sua própria aprendizagem nas interações entre sujeito e objeto, pode-se dizer que a resiliência como processo de superação de dificuldades e contrariedades, não está longe da linha de pensamento Piagetiano, que considera o processo de construção do conhecimento o desequilíbrio entre o sujeito e o objeto. Para ele, a origem do conhecimento por parte do sujeito envolve dois processos complementares e/ou simultâneos. O primeiro é chamado de Assimilação e o segundo a Acomodação, muito semelhante ao conceito de resiliência definido por Tavares (2001). Diante disto, o mundo, a sociedade e todo o contexto de vida colocam o indivíduo frente a um problema, e este indivíduo deverá ser capaz de não apenas resolvê-lo, mas conseguir prosseguir seu caminho levando sobre si o gozo de experimentar e vencer as adversidades que the são colocadas. $O$ sujeito deverá ser ensinado de maneira tal que não se submeta a ser um produto do meio em que vive, mas a partir da própria educação internalizada, deverá receber condições para vencer os desafios que são levantados na vida de qualquer ser humano, e utilizá-los sempre a seu favor e para o bem comum.

A aprendizagem segundo a linha sócio histórica também atenderia à premissa resiliente, uma vez que a aprendizagem nesta linha é uma via de mão dupla, partindo do professor e do mesmo modo do aluno assim como nesta corrente de pensamento. A resiliência exige uma aprendizagem de construção compartilhada, progressista e dialética. Os sujeitos segundo os sócio históricos são interativos, seres sociais construtores da individualidade, mediada pela cultura. A aprendizagem nada mais é que a apropriação de saberes acumulados na história e o ensino a organização da experiência a serem apropriadas. A aprendizagem realiza-se num contexto de interação, através de internalização de instrumentos e signos levando a uma apropriação do conhecimento. A aprendizagem precederia o desenvolvimento, sendo um processo de construção compartilhada, uma construção social. 
A emoção sentida pelo sujeito e objeto (professor/aluno) seria um resultado tanto do aspecto fisiológico, quanto do social. As emoções dependeriam do hábito e do temperamento dos dois. Elas são transformadas nas relações sociais, nas trocas e interações entre pessoas. 0 ensino aprendizagem a luz da resiliência é primordial para a melhor compreensão da relação professor e aluno, que será satisfatória e completa.

\section{5.-Metodologia.}

Conforme Minayo (1999), o tema de uma pesquisa indica a área de interesse a ser investigada, sendo um assunto bastante amplo, faz-se uma delimitação, que neste caso é sobre ensino aprendizagem e resiliência. Partindo daí, surge o problema como um aprofundamento do tema, através de estudos preliminares, individualizado e específico.

A pesquisa é de caráter bibliográfico, cujo levantamento de referências teóricas partiu de trabalhos antes analisados, publicados em formato impresso e eletrônico, como livros, artigos científicos e páginas de web sites, como orienta Fonseca (2002). Os trabalhos são pertinentes, pois permitem discussões a partir de diferentes olhares, diversificando assim a compreensão do ensino aprendizagem.

Essa revisão bibliográfica, foi desenvolvida a partir de "matéria já elaborada, constituídas de livros e artigos científicos" (Gil,2008, p. 50), por meio de artigos encontrados em sites especializados em publicações do gênero, como Scielo e Biblioteca Virtual de Educação e livros que abordem o tema para estruturar a pesquisa.

Utilizou-se uma abordagem qualitativa que busca enfatizar e se preocupa em analisar e interpretar aspectos mais profundos, descrevendo a complexidade do comportamento humano (Marconi; Lakatos, 2011). Essa abordagem possibilita uma análise mais detalhada sobre hábitos, atitudes, tendências de comportamento, sobre aquilo ou quem se deseja investigar. Assim, foram considerados os estudos que contemplam o ensino e aprendizagem e a resiliência.

A abordagem qualitativa vem sendo empregada a partir da década de 1960, no campo educacional. Lüdke e André (1986) ressaltam que essa abordagem permite a compreensão do ambiente escolar em suas peculiaridades estruturais e funcionais, em especial, da relação professores-alunos, neste caso o ensino (professor) e a aprendizagem (aluno).

\section{6.-Conclusão.}

Sendo os professores agentes transformadores a resiliência proporcionaria ao mesmo a certeza da possibilidade real que o seu aluno ou aluna pode sim superar problemas psicossociais; possuindo ferramentas que são oriundas de resiliência pode ser útil a professores, psicólogos, assistentes sociais e profissionais da área da saúde, pois a partir dessas ferramentas é possivel pensar, encontrar forças e recursos nas histórias de crianças e adolescentes para promover seu crescimento e desenvolvimento, além de que "permite aos profissionais da educação encarar de outra forma a evolução de seus alunos, a resiliência é razão para se ter esperança. 
A necessidade de posturas diferentes dos educandos e a maneira como entender 0 processo de resiliência no ambiente escolar podem contribuir para 0 desenvolvimento de conhecimento, fazendo com que os alunos que tenham alguma dificuldade de aprendizado possam acompanhar e melhorar o seu nível de desenvolvimento racional, cientifico e tecnológico, englobando-os numa parceria com os outros alunos e dando-lhe situações problemas para aumenta o seu nível de conhecimento e melhorando a qualidade de ensino.

Acreditamos que a resiliência seja influenciada pela saúde psíquica, inteligência e criatividade, porém não apenas isso. A maneira pela qual vai se superar ou não uma adversidade depende de muitas variáveis, tais como: as circunstâncias (sobretudo de sua primeira infância), pelas mensagens que recebeu, pelas ligações afetivas que criou e a segurança que estas the fizeram sentir. Ou seja, interfere 0 ambiente no qual a pessoa se encontra, a presença ou a ausência de pessoas sadias ao seu redor e o contexto político, religioso, social e cultural no qual se desenvolve, entre outras coisas.

O processo educativo vai sendo construído em meio a contextos históricos que influenciam e são influenciados pela prática formal e informal da educação. 0 momento atual nos mostra um dos maiores desafios a educação, o desenvolvimento de ações que levem a formação integral do indivíduo, como práticas que considerem os saberes sociais construídos, como um todo interligado, no processo de construção global do conhecimento.

Ao buscar no ensino aprendizagem práticas da pedagogia da resiliência, o olhar se volta para as ações do professor quanto a valorização do conhecimento dos alunos, bem como utilização de estratégias que provoquem a interação do aluno no ambiente escolar, instigando-os para um melhor desempenho do ensino-aprendizagem, isso envolve trabalho dinâmico, partindo do método para o conhecimento construído que servirão de base para a construção de novos saberes.

O papel do professor é importante para dar o norte a aprendizagem, tornando-a significativa e contextualizada, transformando a informação em aprendizado. Desse modo, ao fazer uso das estratégias identificadas como da pedagogia da resiliência, percebe-se diferenças em sala de aula, onde os alunos passam a ter maior grau de participação ao desempenhar tarefas estabelecidas. Assim, mudar uma prática pedagógica pode permitir uma integração do aluno ao ensino e o aumento de suas capacidades intelectuais. Portanto a prática pedagógica do professor com aspectos advindos da resiliência, deve ser pensada no processo ensino aprendizagem, em que os alunos possam ter uma melhor qualidade de ensino, por estarem reforçados a relevância de estudos profundos reflexivos em torno de processos pedagógicos resilientes.

\section{7.-Referências Bibliográficas.}

Assis, S.G., Pesce, R., Avanci, J.Q. (2006). Resiliência: enfatizando a proteção dos adolescentes. Porto Alegre: Artmed.

Ferreira, A.B.H. (1999). Novo Aurélio: o dicionário do Século XXI. São Paulo: Nova Fronteira. 
Henderson, N.M. (2004). Resiliência na escola. Buenos Aires: Paidós.

Lakatos, E.M., Marconi, M.A. (2003). Fundamentos de metodologia cientifica. $3^{\circ}$. ed. São Paulo: Atlas.

Libâneo, J.C. (1994). Os métodos de ensino. São Paulo: Cortez.

Melillo, A., Ojeda, E.N. (2005). Resiliência: descobrindo as próprias fortalezas. (V. Campos, trad.). Porto Alegre: Artmed.

Paro, V. (2007). Gestão escolar, Democracia e Qualidade de ensino. São Paulo: Ática.

Pereira, A.M.S. (2001). Resiliência, personalidade, stress, e estratégias de coping. Em J. Tavares (Org.) (2001). Resiliência e educação. São Paulo: Cortez.

Poletto, M., Koller, S.H. (2008). Contextos ecológicos: promotores de resiliência, fatores de risco e proteção. Estudos de Psicologia, edição $n^{\circ} 25$.

Yunes, M.A. (2003). Psicologia positiva e resiliência: o foco no indivíduo e na família. Psicologia em Estudo, $8^{\circ}$ ed. 